\title{
Language disorders in degenerative dementias
}

\author{
A C Bruni \\ From de Senectute: Age and Health Forum \\ Catanzaro, Italy. 5-7 December 2009
}

\section{Background}

Progressive selective deterioration of language is caused by cerebral lesions involved in processes of language elaboration and is characteristic of several forms of dementia such as Alzheimer's disease (AD) and Frontemporal dementia (FTD), that are neurodegenerative dementia and epidemiologically relevant. AD language disturbances are characterized by difficulties in word selection: language becomes impaired, simple and often lacking of syntactic structures.

In the Frontotemporal lobar degeneration spectrum, the language disorder is a key symptom not only for FTD, but also of two specific forms that are Primary Progressive Aphasia and Semantic Dementia. Language disorder is characterised by reduction of verbal initiative evolving towards a complete mutism. Echolalia and perseveration are frequently observed.

In a calabrian population in which FTD is highly prevalent [1], FTD patients have been identified as carriers or non carriers of the Progranulin (GRN) c.1145insA mutation [2].

The patients groups (GRN+ e GRN-) were compared with respect to the language disturbances and age at onset.

\section{Patients and methods}

28 patients (10 GRN+ and $18 \mathrm{GRN}$-; mean age at onset $71.7+11.9$; MMSE $20.9+5.2$ ) were evaluated and, when possible, tests of Phonological Verbal Fluency (PVF) and Categorical Verbal Fluency (CVF) were performed.

\section{Results}

All GRN+ and GRN- patients showed a massive reduction of verbal initiative . GRN+ presented only in 50\% of cases with reduction of verbal initiative, but when the disease became manifest, language was completely lost. All GRN-patients (100\%) at the onset and in the course

Centro Regionale di Neurogenetica, Lamezia Terme, ASP Catanzaro presented with reduction of verbal initiative but without completely losing the language. PVF and CVC in patients able to perform tests (3/10 in GRN+ and 11/18 in GRN-) resulted normal.

The onset of FTD in GRN+ patients was early (64.3 years) compared to GRN-(76.0 years) patients $(\mathrm{p}=0.01)$.

\section{Conclusions}

Language disturbance at onset in both FTD groups was qualitatively impaired and characterized by the massive reduction of verbal initiative evolving differently on the basis of presence/absence of GRN mutation.

Language disturbance evaluation tests were not impaired at onset and did not differentiate the two subgroups. FTD GRN- disease seemed more benign fbecause of the delayed onset and the persistence of the language.

\section{Published: 19 May 2010}

\section{References}

1. Bruni AC, Frangipane F, Colao R, Puccio G, Curcio SAM, Mirabelli M, et al: Epidemiology of Frontotemporal Dementia in Southern Italy. Alzheimer's association International Conference on Alzheimer's Disease, July 11-16, 2009, Vienna, Austria. Alzheimer's and Dementia 2009, 5(4)(Suppl.1): P392-P393.

2. Bruni AC, Momeni P, Bernardi L, Tomaino C, Frangipane F, Elder J, et al: Heterogeneity within a large kindred with frontotemporal dementia: a novel progranulin mutation. Neurology 2007, 69(2):140-147.

doi:10.1186/1471-2318-10-S1-A88

Cite this article as: Bruni: Language disorders in degenerative dementias. BMC Geriatrics 2010 10(Suppl 1):A88. 